\title{
The Governance Effect of Atmospheric Joint Prevention and Control Policy-An Empirical Test Based on Key Prevention and Control Urban Groups
}

\author{
Jingyan Fu, Jiaxin Liu \\ Department of Economy, Jinan University, Guangzhou, China \\ Email: qiao_ljx@126.com
}

How to cite this paper: Fu, J.Y. and Liu, J.X. (2019) The Governance Effect of Atmospheric Joint Prevention and Control Policy-An Empirical Test Based on Key Prevention and Control Urban Groups. Modern Economy, 10, 29-51. https://doi.org/10.4236/me.2019.101003

Received: December 10, 2018

Accepted: January 7, 2019

Published: January 10, 2019

Copyright () 2019 by author(s) and Scientific Research Publishing Inc. This work is licensed under the Creative Commons Attribution International License (CC BY 4.0).

http://creativecommons.org/licenses/by/4.0/

(c) (i) Open Access

\begin{abstract}
This paper selects the key pollutant data of 53 cities in Beijing, Tianjin, Hebei, Yangtze River Delta and Pearl River Delta from 2004 to 2016, and tests the effect of the joint prevention and control policy of the atmosphere on the prevention and control of air pollution in key urban groups. The study found that although China's joint prevention and control mechanism has played a role in preventing and controlling urban emission reduction to a certain extent, the effect is not significant. There are differences in the test results of different pollutants and different regions. The effect of industrial soot emission reduction is not as good as that of sulfur dioxide. The effect of Beijing-Tianjin-Hebei regional policy is the least obvious. From the influencing factors, the growth of per capita income, the environmental awareness of large cities, the Internet communication and participation of residents, and the investment in research and development all significantly promoted the effect of joint prevention and control policies. The green industrial structure is not conducive to the role of policy, but will increase environmental pollution. At the same time, large cities with developed economies are more motivated to promote the implementation of policies. The research in this paper shows that there are still some problems in China's current atmospheric joint prevention and control policy. It can improve the existing mechanism by broadening the main body of governance, forcing industrial upgrading, and focusing on regional differences. This is to promote China. Regional pollution synergy provides a way to support.
\end{abstract}

\section{Keywords}

Atmospheric Joint Prevention and Control Policy, Governance Effect, Key 
Prevention and Control of Urban Agglomeration

\section{Introduction}

As an important environmental policy implemented by the state since the "Twelfth Five-Year Plan", the joint prevention and control of regional air pollution is a research and practice that has emerged as a result of China's current regional and complex characteristics of air pollution [1] [2]. It makes up for the shortcomings of the simple total control system of administrative units as the unit and can only control the simple point source local pollution, and is more targeted to air pollution control. The operation of the regional joint prevention and control mechanism aims to break through the administrative boundaries and use the region as an overall unit to jointly plan and supervise each other and share regional governance results. The Party Central Committee and the State Council have attached great importance to regional air pollution prevention and control and made a series of important arrangements. In May 2010, the Ministry of Environmental Protection and other nine ministries and commissions jointly formulated the "Guiding Opinions on Promoting Air Pollution Joint Prevention and Control Work to Improve Regional Air Quality". On the basis of fully absorbing domestic and international environmental management experience, it was proposed that "by 2015, Establish a 'work objective of air pollution joint prevention and control mechanism"'. In December 2012, the State issued the "Twelfth Five-Year Plan for Air Pollution Prevention and Control in Key Areas", which provided policy support for the rapid and effective promotion of "linkage" in various regions. In June 2013, the State Council issued the "National Ten Articles" for the prevention and control of atmospheric pollution, and listed the "Joint Mechanism for the Joint Prevention and Control of the Bohai Sea, including the Beijing-Tianjin-Hebei, the Yangtze River Delta, and the Pearl River Delta" as a separate measure, officially marking the China United Defense Association. Control the formation of air pollution management models. At the same time, on the basis of the successful experience of developed countries, China has also carried out the practice of joint prevention and control of regional joint defense. The most representative ones are the large-scale air quality assurance actions such as the 2008 Beijing Olympic Games, the 2010 Shanghai World Expo and the 2010 Guangzhou Asian Games. These practices have improved the air quality in a short period of time and laid a solid foundation for the construction of China's joint defense and related policies and management mechanisms. However, due to the lack of guarantees and continuous long-term mechanisms, the air quality in the short term has not been continuously improved. Therefore, at this stage, we must fundamentally improve the situation of China's poor air quality. We must further study key influencing factors and find policy breakthroughs. 
At present, the cooperation mechanism for air pollution control in China has been initially established, but there are still many shortcomings, such as measures such as production stoppages and motor vehicle restrictions, such as refinement, pollution prevention and control information cannot be shared, industrial structure and economic development lack regional overall planning, etc. Therefore, it is necessary to explore the organization and coordination mechanism for the construction of air pollution control, the compensation mechanism for interest coordination and the public participation mechanism. Considering the coordinated management of air pollution, on the one hand, it will help to improve the efficiency and effectiveness of regional air pollution government coordinated governance, and promote the modernization of the national comprehensive governance system and governance capacity; on the other hand, it will be implemented in May 2017 with the Central Deep Reform Group meeting. The "Pilot Program for Cross-Regional Environmental Protection Organizations" and the National "Thirteenth Five-Year Plan" and other proposals for "establishing cross-regional environmental protection agencies and implementing a cross-regional joint prevention and control joint governance model” are consistent.

Although the environmental protection departments have achieved some results in promoting regional and river basin management, some local governments are not in line with each other because of their respective development stages and interests, which makes it difficult to unify the environmental protection objectives, policy standards, and law enforcement standards. For the implementation of the "Atmosphere Ten", the Beijing-Tianjin-Hebei and surrounding areas have established a joint meeting system for regional air pollution prevention leading groups. The joint meeting is attended by the people's governments of the provinces (autonomous regions and municipalities) and the relevant departments of the State Council. Through regular leadership group meetings and office work meetings, the two major forms are studied and coordinated to solve outstanding environmental problems in the region, and the implementation of environmental assessment meetings and associations is organized. Air pollution prevention and control measures such as law enforcement, information sharing, and early warning and emergency response. However, this coordination group, as a coordination mechanism, can only play a coordinating role. Without specific functions, it is impossible to formulate unified planning, unified standards, unified environmental assessment, and unified monitoring, so that the joint control of air pollution prevention and control in the Beijing-Tianjin-Hebei region is greatly reduced. The Ministry of Environmental Protection has also promoted local environmental protection duties through law enforcement and supervision by the six environmental protection inspection centers sent by the whole country. However, these supervision centers, as the dispatching agencies of the central environmental protection agencies to supervise the law enforcement functions, still have relatively weak institutional arrangements and lack of management. The function is different from the function 
positioning of the real regional environmental protection agency. Therefore, these problems cannot be solved by a single region or city. It is often necessary to break the administrative boundaries and create a model of intergovernmental coordination.

This dilemma has also become the direct cause of the establishment of the first cross-regional environmental protection agency in the Beijing-Tianjin-Hebei region. On the 6th of 2017, the Ministry of Environmental Protection's deep reorganization meeting decided: 1 to implement the "Pilot Program for Cross-Regional Environmental Protection Organizations", clarifying that the organization is called the Beijing-Tianjin-Hebei Environmental Protection Bureau, and the organization is located in the Ministry of Environmental Protection, and strives to complete the preparatory formation before the end of September. And trial operation; the end of June 2018 needs to complete the environmental management vertical management reform tasks as required. The decision underscores the will of the country's cross-regional + sag to control smog and other atmospheric pollution. The Beijing-Tianjin-Hebei Environmental Protection Bureau will also become China's first cross-regional environmental protection agency to address regional atmospheric environmental issues. This is also the 2015 "Overall Plan for the Reform of Ecological Civilization System", which proposes "innovation pilots for environmental protection management systems in some regions, unified planning, unified standards, unified environmental assessment, unified monitoring, and unified law enforcement". The national "Thirteenth Five-Year Plan" proposed "exploring the establishment of cross-regional environmental protection institutions" and took a substantial step. Inter-government collaborative governance needs to be united through contracts or mechanisms to jointly manage public affairs in the region through a holistic governance concept and establish a long-term and stable cooperative relationship.

This paper attempts to answer the following questions by quantitatively measuring the effectiveness of the joint prevention and control policies in the three major regions, and further analyzing the relevant factors affecting the implementation of the joint prevention and control policy. 1) The current joint defense and control policy in air pollution control Have you achieved the expected results? 2) What are the main factors affecting air pollution control in the region? What promotes the policy and what hinders the policy? 3) In what areas should future regional collaborative governance work? On the one hand, this paper can provide a way to support the effective implementation of the air pollution prevention and control joint control policy, on the other hand, it can also help improve the governance effect of regional pollution cooperation in China, and provide reference for relevant policy makers.

The rest of the paper is organized as follows: The second part describes the current research situation of joint prevention and control of regional air pollution joint control at home and abroad; the third part introduces the empirical methods, data, variables, etc.; the fourth part presents empirical test and analyzes the empirical results. The fifth part is conclusions and policy recommendations. 


\section{Literature Review}

Through the collection and collation of the literature, the academic research on the joint control of regional air pollution joint defense is roughly divided into the following three categories:

The first type of research takes the issue of cross-regional environmental governance as the starting point and discusses the necessity of collaboration between different regional governments for regional pollution control. Some scholars believe that regional air pollution is fluid, and its governance should not only affect the interests of one region, but also the interests of other relevant regions. Therefore, its governance requires cross-regional government collaboration [3] [4]. With the deepening of research, another part of the scholars analyzed the internal policy process by studying the cooperative governance mechanism of transboundary pollution, and believed that cross-border pollution governance is a proposition with both political science and economics, and it proposed the coordination of interests [5] [6] [7] [8] [9].

On the basis of the first type of research, the second type of research believes that regional cooperation is the necessary way for regional air pollution control, and analyzes the current status of air pollution prevention and control, and how to build long-term effects around regional environmental pollution control practices. About the cooperation mechanism, some scholars have discussed the practical experience of regional environmental cooperation in developed countries such as the United States and the European Union, and discussed their implications for the joint control practice of China's joint defense. First, the United States has accumulated rich experience in environmental collaborative governance. The US Interstate Agreement has become the most important mechanism for interstate cooperation and interstate disputes. Scholars summarize the basic state and experience of the US Interstate Agreement and the regional management of air quality management and ozone pollution in Southern California, and discuss the regional environment of China. Moreover, they also have discussed the key factors and management systems of air quality [10] [11]. Secondly, in order to jointly promote the solution of air pollution in Europe, in November 1979, 34 European countries signed the Convention on Long-Range Transboundary Air Pollution in Geneva. Scholars have summarized the framework of the European Air Pollution Convention framework and proposed how to build a long-term regional cooperation mechanism for air pollution prevention and control [12]. Another part of the scholars analyze the status quo of air pollution control in key areas of China, and make a reflection on the theory and practice of the joint prevention and control mechanism of the domestic regional joint defense. First of all, air pollution control is a key and difficult problem that must be solved in the process of coordinated development of Beijing-Tianjin-Hebei. Scholars analyze the current situation of joint action of air pollution prevention and control in Beijing-Tianjin-Hebei, and believe that policy coordination in government collaboration is the key to integrated governance. At the same time, 
we must pay more attention to the role of market mechanisms and focus on interest coordination [13] [14]. Secondly, the Yangtze River Delta is one of the most developed regions in China. The rapid development of the economy has also made the air pollution situation in the region more and more serious. Scholars have pointed out the construction of a long-term pollution prevention and coordination mechanism by analyzing the practice of coordinated governance in the Yangtze River Delta region [15]. While exploring the role of the new approach to market mechanisms to address regional pollution problems [16] [17]. In addition, due to the large economic volume and high concentration of pollution sources, the Pearl River Delta region has also become the key prevention and control area for joint prevention and control of air pollution in China. Scholars have analyzed the practice of environmental cooperative management in the Pearl River Delta region from the analysis of numerical simulation and current status of sources [18], mechanism operation, legislation [19] [20] and other perspectives on the institutional arrangements for environmental cooperation in the Pearl River Delta region.

With the gradual deepening of research, the third type of research is based on the first two categories, combined with the consideration of constructing a long-term mechanism for regional environmental cooperative governance, and analyzes various incentives supported by the air pollution prevention and control joint control policy. How to provide incentives for the long-term mechanism of joint prevention and control policies [21]. From the perspective of government management, some scholars believe that pollution tax can increase the relative cost and price of pollution activities, and achieve the incentive to effectively alleviate environmental pressure by implementing the principle of "polluter pays" [22] [23]. Another group of scholars believe that it is far from enough to control air pollution by means of traditional command and control mode, that is, collecting pollution taxes and fees. It is also necessary to introduce market mechanisms, such as emission trading mechanisms [24]. It has become a new way for local governments to solve regional environmental pollution problems. In addition, scholars also discussed the "regional ecological compensation" model of air pollution collaborative governance combined with China's unique regional system, and discussed the necessity of regional environmental cooperation horizontal compensation [25] [26] [27]. Some scholars also focus on the current situation of China's air pollution prevention and control legislation, and propose corresponding legislative improvement suggestions [28] [29] [30] [31] to provide legal guarantee mechanism for regional joint prevention and control practice.

However, in general, there are still some places worth exploring: 1) The existing government and market means for the joint prevention and control of various air pollution are limited to the principled opinions, but there is no specific content of the regional pollution control mechanism and methods. Based on this, the marginal contribution of this paper is to provide a specific direction for 
regional collaborative governance by quantitatively analyzing the factors that currently affect the effectiveness of China's joint defense joint control policy, such as public participation. 2) In the prevention and control of regional pollution, most of the existing researches focus on the analysis of incentives and long-term mechanisms, and the emphasis on public power is insufficient. The public's awareness of air pollution and the demand for air quality, as well as the attention, supervision and participation of the central government in formulating policies and local government implementation policies, will exert pressure and binding on government policies. This will have an important impact on the depth and breadth of regional pollution control cooperation. Therefore, this paper joins the public participation variable to verify the impact of the public's power on the effectiveness of the joint defense policy. 3) Although the research has demonstrated the necessity of joint prevention and control mechanism of air pollution, and proposed a path plan for establishing a long-term mechanism, there is little literature to empirically examine the implementation effect of the joint prevention and control mechanism of regional air pollution. In this regard, this paper takes the key areas of the implementation of China's joint defense joint control (Beijing-Tianjin-Hebei, Yangtze River Delta, Pearl River Delta) as an example, based on the key pollutants (sulphur dioxide, industrial soot) to be controlled by the joint prevention and control mechanism, empirically tested the regional joint defense The implementation effect of the joint control mechanism.

\section{Research Method}

\subsection{Model Design}

Based on the actual situation of key prevention and control of urban agglomerations, this paper studies the difference of air pollution control effects between urban agglomerations in different regions and cities with different economic development levels, and uses this as an opportunity to explore the influencing factors of air pollution control in urban agglomerations. This paper selects two key pollutants, namely sulfur dioxide and industrial soot, as the research object, and studies the emission reduction effect of the joint prevention and control policy of the atmosphere on the three key prevention and control urban agglomerations, and analyzes the related factors affecting pollution reduction.

This paper mainly studies the emission reduction effects of the air pollution prevention and control joint control on the three key governance areas of Beijing-Tianjin-Hebei, Yangtze River Delta and Pearl River Delta and the related factors affecting the emission reduction effect. First, based on the changes in emission intensity of sulfur dioxide and industrial soot pollutants in 53 cities in the three major urban agglomerations of Beijing-Tianjin-Hebei, Yangtze River Delta and Pearl River Delta in 2004-2016, explore whether the joint prevention and control policies will produce key pollutants in the three key prevention and control areas. A better emission reduction effect, analysis of the differences in emission reductions of urban pollutants in different regions, and analysis of re- 
levant factors affecting pollution reduction, this paper divides 53 cities in the three major urban agglomerations of Beijing-Tianjin-Hebei, Yangtze River Delta and Pearl River Delta into 13 Beijing-Tianjin-Hebei cities, 26 Yangtze River Delta cities and 14 Pearl River Delta cities; secondly, based on annual per capita GDP level in the latest year of the National Bureau of Statistics, the 53 cities are divided into 29 high-economic cities and 24 low- and middle-level cities, study the impact of economic level differences on key pollution prevention and control of urban agglomeration, in order to verify the environmental Kuznets curve hypothesis that economically developed large cities are less environmentally friendly than small and medium-sized cities. Lower, the policy implementation effect is better; finally, based on the empirical results, the policy recommendations to improve the existing regional joint prevention and control mechanism, and then promote the coordinated management of air pollution in China, provide reference for government policy makers.

In the selection of the panel data model, the F test and the Hausmann test are respectively carried out, and the null hypothesis of accepting the mixed regression model and the random effect model is rejected in turn. Finally, the fixed effect model (FE) is selected for the joint defense. The joint control policy is used to estimate the emission reduction effects of key pollutants. Based on the above analysis, the regression model is constructed as follows:

$Y_{i t}=\beta_{0}+\beta_{1}$ Policy $_{t}+\beta_{2} \mathrm{YRD}_{i} \times$ Policy $_{t}+\beta_{3}$ PRD $_{i} \times$ Policy $_{t}+\beta_{4} X_{i t}+\mu_{i}+\eta_{t}+\varepsilon_{i t}(1)$

$i$ and $t$ respectively represent the $t$-th year of the $i$-th city; the explanatory variable $Y$ represents the unit discharge intensity of urban pollutants. This paper separately collects the annual emissions data of sulfur dioxide and industrial soot in each city, and collects and sorts the cities. Gross domestic product (GDP) calculates the unit emission intensity (ton/100 million GDP) of sulfur dioxide and industrial soot in each city, respectively, expressed by SI and MI. Policy ${ }_{t}$ represents the joint prevention and control policy of the atmosphere. The "Air Pollution Prevention and Action Plan" (Atmosphere "National Ten"), which was issued in 2013, marks China's entry into the comprehensive prevention and control phase of air pollution prevention and control. Therefore, when $t<2013$, Policy $_{t}=0$, when $t \geq 2013$, Policy $=1 . \mathrm{YRD}_{i}$ and $\mathrm{PRD}_{i}$ are the regional dummy variables of city $i$. When $\mathrm{YRD}_{i}=1$ and $\mathrm{PRD}_{i}=0$, city $i$ is located in the Yangtze River Delta region; when $\mathrm{YRD}_{i}=0$ and $\mathrm{PRD}_{i}=1$, city $i$ is located in the Pearl River Delta region, when $\mathrm{YRD}_{i}=0$ and When $\mathrm{PRD}_{i}=0$, city $i$ is located in the Beijing-Tianjin-Hebei region. $X_{i t}$ represents other control variables. In the specific process of analyzing policy effects, this paper introduces relevant influencing factors as control variables into the model for analysis. $I_{i}$ and $\eta_{t}$ represent time fixed effects and individual fixed effects, respectively, $\varepsilon_{i t}$ is a random error term, and $\beta_{0}$ is a constant term.

Regarding the control variables, this paper makes the following selections: 1) Economic factors: This paper selects the per capita GDP (PGDP) and the secondary industry output value (STR). The former measures the comprehensive 
economic development level and the per capita wealth impact of each region. The latter to measure the impact of the secondary industry on pollutant emissions, from the perspective of industrial structure, China's industrial sewage discharge accounts for the largest proportion of total pollutant emissions. Therefore, this paper selects the proportion of secondary industry as an industrial structure indicator. 2) Social factors: This paper selects population density (POP), urbanization level (UR), social capital (SC), and fiscal expenditure scale (FE), in which population density (POP) and urbanization level (UR) are measures of population size. The impact indicator, the former reflects the ratio of the total population of each region to the land area of the local administrative region, and measures the impact of the total population on the environment. The latter reflects the ratio of the urban population to the total population of the region, and measures the impact of the urban population on the environment; With the continuous advancement of technology, the Internet has become the main channel for the public to participate in government decision-making, and the public has become an important part of the multi-governance of the public environment. Therefore, based on the practices of [32] and [33], this paper selects The proportion of the number of network users in each region to the total population of the region indicates the degree of information sharing and network communication among residents in each region, as an indicator to measure social capital (SC). At the same time, this paper also selects the indicator of fiscal expenditure scale (FE). Use local government fiscal expenditure to study the relationship between local government financial input and environmental quality management. 3) Technical factors: This paper selects R \& D intensity (RD) and technical import (FI) to measure the impact of technology level on the environment. The former is represented by the ratio of science and technology expenditure to GDP in each region, and the latter is calculated by the actual use of foreign capital in each region. The ratio shows that this is because China's technical import is mainly realized through the form of foreign direct investment.

\subsection{Data and Description Statistics}

The panel data observation section used in this paper is 53 cities in the three major urban agglomerations of Beijing-Tianjin-Hebei, Yangtze River Delta and Pearl River Delta. In order to obtain more complete year data, the time span is from 2004 to 2016. The initial data is derived from the city statistical yearbook and the China Urban Statistical Yearbook, and the following indicators are obtained. The data used in this paper includes sulfur dioxide emissions, industrial soot emissions, per capita GDP, secondary industry structure, population density, and urbanization levels. The relevant descriptive statistics are shown in Table 1 .

\section{The Analysis of Empirical Results}

This section mainly reports model results and draws conclusions. First of all, 
Table 1. Descriptive statistics of variables.

\begin{tabular}{|c|c|c|c|c|c|c|c|}
\hline Variable & Unit & Symbol & Mean & $\begin{array}{l}\text { Standard } \\
\text { deviation }\end{array}$ & $\begin{array}{l}\text { Minimum } \\
\text { value }\end{array}$ & \multicolumn{2}{|c|}{ Maximum Observation } \\
\hline \multicolumn{8}{|l|}{$\begin{array}{l}\text { Dependent } \\
\text { variable }\end{array}$} \\
\hline $\begin{array}{l}\mathrm{SO}_{2} \text { emission } \\
\text { intensity }\end{array}$ & $\begin{array}{l}\text { Tons } / 100 \\
\text { million yuan }\end{array}$ & SI & 50.4599 & 55.3349 & 0.2361 & 503.9894 & 689 \\
\hline $\begin{array}{l}\text { Soot emission } \\
\text { intensity }\end{array}$ & $\begin{array}{l}\text { Tons } / 100 \\
\text { million yuan }\end{array}$ & MI & 24.6857 & 64.1891 & 0.0453 & 1487.365 & 689 \\
\hline \multicolumn{8}{|l|}{$\begin{array}{l}\text { Independent } \\
\text { variable }\end{array}$} \\
\hline $\begin{array}{l}\text { Yangtze River } \\
\text { Delta }\end{array}$ & - & YRD & 0.4906 & 0.5003 & 0 & 1 & 689 \\
\hline Pearl River Delta & - & PRD & 0.2642 & 0.4412 & 0 & 1 & 689 \\
\hline Policy & - & Policy & 0.3077 & 0.4619 & 0 & 1 & 689 \\
\hline Control variable & & $\mathrm{X}$ & & & & & \\
\hline Per capita GDP & Yuan & PGDP & 46699.16 & 37733.34 & 4111 & 467749 & 689 \\
\hline $\begin{array}{l}\text { Industrial } \\
\text { structure }\end{array}$ & $\%$ & STR & 50.7073 & 8.2674 & 19.74 & 74.73 & 689 \\
\hline $\begin{array}{l}\text { The population } \\
\text { density }\end{array}$ & Person $/ \mathrm{km}^{2}$ & POP & 618.1452 & 348.5712 & 90.79 & 2661.54 & 689 \\
\hline $\begin{array}{l}\text { The level of } \\
\text { urbanization }\end{array}$ & $\%$ & UR & 0.4248 & 0.2634 & 0.0708 & 1.0101 & 689 \\
\hline Social capital & $\%$ & SC & 0.2098 & 0.2759 & 0.0045 & 3.6635 & 689 \\
\hline $\begin{array}{c}\text { Financial } \\
\text { expenditure }\end{array}$ & $\begin{array}{l}\text { Hundred } \\
\text { million yuan }\end{array}$ & $\mathrm{FE}$ & 372.8035 & 680.5838 & 9.2022 & 6191.56 & 689 \\
\hline R \& D intensity & $\%$ & $\mathrm{RD}$ & 0.0206 & 0.0196 & 0.0004 & 0.2068 & 689 \\
\hline Technical import & $\%$ & FI & 0.0326 & 0.0216 & 0.0007 & 0.129 & 689 \\
\hline
\end{tabular}

Source: Author calculation.

according to the regional overall results, the results show that from the perspective of policy effects, the overall effect of joint prevention and control policies is not significant. Among them, the industrial dust emission reduction after the implementation of the joint prevention and control policy is generally not as good as the reduction of sulfur dioxide; the Beijing-Tianjin-Hebei region is the least optimistic region in the three major regions. Secondly, the results of sub-regional regression show that the joint prevention and control policy has a significant effect on the reduction of sulfur dioxide in economically developed cities, but the effect of the policy on industrial smoke emission is not significant regardless of the economic level. Beijing-Tianjin-Hebei region has the weakest effect for emission reduction in the three regions. In addition, from the influencing factors, the growth of per capita living standards and the process of urbanization can promote the reduction of urban pollutants regardless of the level of economic level; while the traditional non-green industrial structure dominated 
by the secondary industry is not conducive to pollution reduction.

In order to avoid the pseudo-regression problem often appearing in the panel data model and ensure the validity of the estimation results, the unit root test is carried out for each variable. The test methods used include: LLC test, Fisher-type ADF test and Hadri LM test. After the variables are added to the trend term processing, all variables are zero-order stationary sequences, so they can be used for model estimation. In order to reduce the collinearity and heteroscedasticity of the model and increase the data stationarity, the variables in addition to the dummy variables are processed in logarithm.

\subsection{Regional Overall Results}

This section studies the overall situation of pollution reduction in the three major regions, using the sulphur dioxide emission intensity log lnSI and the industrial soot emission intensity $\log \ln \mathrm{MI}$ to measure pollution reduction. The results are shown in Table 2.

There are some differences in the results of using two pollutants to measure pollution reduction. When the sulphur dioxide emission intensity $\log \ln S I$ is used to indicate the pollution reduction, the results of the models (1) and (2) show that the impact of the policy on sulfur dioxide emission reduction is not significant, although it has an inhibitory effect, but the effect is not obvious. The difference in the impact of urban location factors on sulfur dioxide emission reduction is not significant. Compared with the Beijing-Tianjin-Hebei region, the implementation of the joint prevention and control policy in the Yangtze River Delta region and the Pearl River Delta region has a greater inhibitory effect on sulfur dioxide emissions than the Beijing-Tianjin-Hebei region. Regional sulfur dioxide emissions have the weakest effect.

From the perspective of relevant control variables: 1) Economic factors. The per capita GDP coefficient is negative in the models (1) and (2). In the model (1), the coefficient is significantly negative at the $10 \%$ level, which indicates that the growth of per capita living standards will reduce the intensity of sulfur dioxide emissions, but in control After the time effect, its inhibition of sulfur dioxide is not significant. The ratio of the proportion of the secondary industry is significantly positive in the models (1) and (2), which indicates that the higher the proportion of the secondary industry, the greater the intensity of sulfur dioxide emissions. 2) Social factors. The population density coefficient is negative, which may be due to the higher the population density, the stronger the government's environmental regulation awareness, and the greater the intensity of environmental pollution control [34]. The urbanization level coefficient is significantly negative, which reflects the economies of scale and concentration brought about by urban concentration and industrial concentration, which greatly enhances productivity, enhances economic strength, and advances in science and technology to help solve environmental pollution problems. The social capital coefficient is negative, indicating that the higher the social capital, 
Table 2. Regional overall regression results.

\begin{tabular}{|c|c|c|c|c|}
\hline & \multicolumn{2}{|c|}{$\begin{array}{l}\text { Sulfur dioxide emission intensity } \\
\qquad \operatorname{lnSI}\end{array}$} & \multicolumn{2}{|c|}{$\begin{array}{l}\text { Industrial soot emission intensity } \\
\qquad \operatorname{lnMI}\end{array}$} \\
\hline & Model (1) & Model (2) & Model (1) & Model (2) \\
\hline \multicolumn{5}{|c|}{ Independent variable } \\
\hline Policy $_{t}$ & $\begin{array}{c}-0.0562 \\
(-0.72)\end{array}$ & $\begin{array}{c}-0.7628 \\
(-1.36)\end{array}$ & $\begin{array}{c}0.5087^{* *} \\
(2.60)\end{array}$ & $\begin{array}{l}0.6305 \\
(0.62)\end{array}$ \\
\hline $\mathrm{YRD}_{i} \times$ Policy $_{t}$ & $\begin{array}{c}-0.0823 \\
(-0.95)\end{array}$ & $\begin{array}{l}-0.0678 \\
(-0.79)\end{array}$ & $\begin{array}{l}-0.2638 \\
(-1.14)\end{array}$ & $\begin{array}{c}-0.3065 \\
(-1.32)\end{array}$ \\
\hline $\mathrm{PRD}_{i} \times$ Policy $_{t}$ & $\begin{array}{c}-0.0810 \\
(-0.66)\end{array}$ & $\begin{array}{c}-0.0716 \\
(-0.59)\end{array}$ & $\begin{array}{c}-0.1703 \\
(-0.59)\end{array}$ & $\begin{array}{c}-0.2058 \\
(-0.69)\end{array}$ \\
\hline \multicolumn{5}{|l|}{ Control variable } \\
\hline $\ln \mathrm{PGDP}_{i t}$ & $\begin{array}{l}-0.3019^{*} \\
(-1.82)\end{array}$ & $\begin{array}{l}-0.3224 \\
(-1.63)\end{array}$ & $\begin{array}{c}-0.8729^{* \star \star} \\
(-4.94)\end{array}$ & $\begin{array}{c}-0.8490^{\star * *} \\
(-4.46)\end{array}$ \\
\hline $\operatorname{lnSTR} \operatorname{Tit}_{i t}$ & $\begin{array}{c}1.9302^{\star * *} \\
(4.63)\end{array}$ & $\begin{array}{c}1.5978^{\star * *} \\
(3.45)\end{array}$ & $\begin{array}{c}1.5759^{* *} \\
(2.48)\end{array}$ & $\begin{array}{c}1.6840^{* *} \\
(2.41)\end{array}$ \\
\hline $\operatorname{lnPOP}_{i t}$ & $\begin{array}{c}-0.5553 \\
(-1.29)\end{array}$ & $\begin{array}{c}-0.5333 \\
(-1.23)\end{array}$ & $\begin{array}{c}-0.9984 \\
(-1.23)\end{array}$ & $\begin{array}{c}-0.9603 \\
(-1.18)\end{array}$ \\
\hline $\ln \mathrm{UR}_{i t}$ & $\begin{array}{c}-0.1938^{* * *} \\
(-3.34)\end{array}$ & $\begin{array}{c}-0.2360^{* * *} \\
(-3.83)\end{array}$ & $\begin{array}{c}-0.0921 \\
(-0.51)\end{array}$ & $\begin{array}{c}-0.1912 \\
(-1.03)\end{array}$ \\
\hline $\operatorname{lnSC} C_{i t}$ & $\begin{array}{c}-0.0614 \\
(-1.08)\end{array}$ & $\begin{array}{c}-0.0173 \\
(-0.30)\end{array}$ & $\begin{array}{l}-0.1432 \\
(-1.48)\end{array}$ & $\begin{array}{l}-0.1537 \\
(-1.52)\end{array}$ \\
\hline $\operatorname{lnFE} E_{i t}$ & $\begin{array}{c}-0.3503^{* *} \\
(-2.35)\end{array}$ & $\begin{array}{c}-0.0142 \\
(-0.06)\end{array}$ & $\begin{array}{l}0.2944 \\
(1.51)\end{array}$ & $\begin{array}{l}0.2174 \\
(0.57)\end{array}$ \\
\hline $\operatorname{lnRD}_{i t}$ & $\begin{array}{c}-0.0685^{\star *} \\
(-2.32)\end{array}$ & $\begin{array}{c}-0.0832^{*} \\
(-1.75)\end{array}$ & $\begin{array}{c}-0.1308^{* * *} \\
(-3.07)\end{array}$ & $\begin{array}{l}-0.0427 \\
(-0.50)\end{array}$ \\
\hline $\operatorname{lnFI}_{i t}$ & $\begin{array}{l}-0.0007 \\
(-0.01)\end{array}$ & $\begin{array}{l}-0.0364 \\
(-0.72)\end{array}$ & $\begin{array}{l}-0.0759 \\
(-1.00)\end{array}$ & $\begin{array}{l}-0.0662 \\
(-0.86)\end{array}$ \\
\hline Constant term & $\begin{array}{l}3.7868 \\
(1.04)\end{array}$ & $\begin{array}{l}3.5342 \\
(0.99)\end{array}$ & $\begin{array}{r}8.8953 \\
(1.45)\end{array}$ & $\begin{array}{l}8.6585 \\
(1.41)\end{array}$ \\
\hline Time Effect & & $\sqrt{ }$ & & $\sqrt{ }$ \\
\hline Individual Effect & $\sqrt{ }$ & $\sqrt{ }$ & $\sqrt{ }$ & $\sqrt{ }$ \\
\hline Observations & 689 & 689 & 689 & 689 \\
\hline Within $\mathrm{R}^{2}$ & 0.7636 & 0.7838 & 0.2962 & 0.3465 \\
\hline
\end{tabular}

Note: 1$)$ The values in parentheses are t values; 2 ) ${ }^{* * *},{ }^{* *}$, and ${ }^{*}$ indicate significant statistical levels at $1 \%$, $5 \%$, and $10 \%$, respectively; 3 ) All models consider heteroscedasticity, Statistical inference was made using clustering robust standard errors with clustering variables for each city. Source: Author use stata14.0 software to calculate.

that is, the higher the degree of communication and information sharing among residents, the greater the opportunity for the public to participate in the government's emission reduction policies, and the suppression of sulfur dioxide pollution. The fiscal expenditure coefficient is negative, and is significantly negative in model (1), indicating that government fiscal input can reduce sulfur dioxide pollution to some extent. 3) Technical factors. The strength coefficient of $\mathrm{R}$ \& $\mathrm{D}$ is significantly negative, which indicates that environmental protection needs to rely on scientific and technological input, and the increase in R \& D in- 
vestment reduces the intensity of sulfur dioxide emissions. The technical import coefficient is negative. The possible reason is that China has introduced advanced technology, especially environmental protection technology, by using foreign capital, which has promoted the reduction of sulfur dioxide to some extent.

When using the industrial soot emission intensity $\log \ln M I$ to measure pollution reduction, it is found that the policy coefficient is positive in the models (1) and (2), and is significant in the model (1), reflecting the implementation of policies in each region. Afterwards, industrial dust pollution has not been inhibited as a whole, and the effect of the policy on the side is not obvious. It also reflects that the emission reduction of cities is not as optimistic as the reduction of sulfur dioxide. This may be due to the fact that China's current desulfurization technology is relatively mature, and industrial soot mainly comes from industrial enterprises. At present, most industrial power plant dust removal equipments need to be dedusted, and industrial enterprises need a large amount of dust removal to achieve low emissions. Dust emission reduction is a major difficulty in current environmental protection policies. The difference of urban location factors on industrial soot emission reduction is not significant, indicating that there is no significant superposition effect between the implementation of policies and different regions, but compared with the Beijing-Tianjin-Hebei region, the Yangtze River Delta region and the Pearl River Delta region implement joint prevention and control. The policy has a greater inhibitory effect on industrial soot emissions than the Beijing-Tianjin-Hebei region. The industrial dust emission reduction effect in the Beijing-Tianjin-Hebei region is the weakest, which is similar to the previous research results.

From the perspective of other control variables: 1) Economic factors. The per capita GDP coefficient is significantly negative in models (1) and (2), which indicates that the growth of per capita living standards significantly reduces the intensity of urban industrial soot emissions, indicating that with the improvement of economic level, residents have higher requirements for environmental quality. To some extent, pollution emissions are suppressed. This is in line with the view of the environmental Kuznets curve (EKC) theory that there is a " $U$ "-type relationship between environmental pollution and economic growth. When the economy develops to a certain extent, there will be an inflection point, so that environmental pollution will live with per capita life. The level of growth decreases. Compared with developed countries, although China's economic development level is still in the left half of the EKC curve, relevant scholars still use empirical results to support the two-way role of China's economic growth and pollution emissions [35]. The ratio of the proportion of the secondary industry is significantly negative, indicating that the development of traditional non-green industries has increased industrial soot pollution, similar to the previous research results. 2) Social factors. The population density coefficient is negative, which reflects that in large cities with higher population density, the government 
has a stronger awareness of environmental regulations and higher environmental standards, which has inhibited industrial soot emissions, similar to the previous results. The urbanization level coefficient is negative, indicating that the urbanization process has played a positive role in the reduction of soot emissions to a certain extent, similar to the previous results. The social capital coefficient is negative, similar to the previous results, reflecting that network information sharing is conducive to residents' participation in government emission reduction policies. The fiscal expenditure coefficient is positive, indicating that fiscal input has not played a role in reducing emissions from industrial soot pollution. 3) Technical factors. The R \& D intensity coefficient is negative and significant in model (1), indicating that $\mathrm{R} \& \mathrm{D}$ investment is conducive to industrial soot emission reduction. The technical import coefficient is negative, similar to the previous results, indicating that the introduction of foreign capital technology has a certain inhibitory effect on industrial soot pollution.

In summary, the paper draws: 1) From the perspective of policy effects, the overall effect of joint prevention and control policies is not significant, and the overall results are similar to that of [36]. Among them, the industrial dust emission reduction after the implementation of the joint prevention and control policy is generally not as good as the reduction of sulfur dioxide; the Beijing-Tianjin-Hebei region is the least optimistic region in the three major regions. 2) From the influencing factors, the growth of per capita living standards, the environmental awareness of large cities, the Internet communication and participation of residents, and the investment in research and development can all promote the emission reduction effect of pollutants; while the traditional industries are mainly non-green. The industrial structure is not conducive to pollution reduction, on the contrary, it will aggravate environmental pollution; although the financial input has not played a role in reducing the emission of industrial soot, it can promote the reduction of sulfur dioxide, which also reflects from the side that the current industrial dust emission reduction situation is pessimistic, the government should increase environmental protection investment in industrial dust emission reduction.

In fact, although the practice of joint control and coordinated governance in China's joint defense is constantly enriched, there are still many problems. 1) On the macro level, the top-level design is unscientific and lacks incentives. First of all, China's air pollution joint defense control system still lacks a scientific top-level design. Although local governments in the Beijing-Tianjin-Hebei, Yangtze River Delta and Pearl River Delta regions have achieved some practical results in collaboration and pollution control, in general, the central government Unified coordination still plays a leading role. Since China is a unitary state, all local governments are only the organs of the central government and accept the unified leadership of the central government. In the actual cross-regional air pollution prevention and control process, the economic level and environmental protection appeals of local governments are not the same, and the opinions and 
interests of all parties are difficult to coordinate. Secondly, the regional joint defense and joint market incentive mechanism for effective operation has not yet been established. Due to the lack of effective implementation of environmental economic policy tools, it is difficult to resolve the cost sharing and the synergy of major interests in the deep system of regional coordinated governance. When economic interests cannot be coordinated, governance will lack continuity and it will be difficult to form a long-term mechanism for cooperation. 2) On the middle level, regional cooperation is not deepened and the main body of governance is single. China's administrative system is in the form of a pyramid, forming a structural model that combines vertical and horizontal juxtaposition. Each department has its own political affairs, completes its work independently, and has less cooperation between departments. The environmental protection is different, and the fields and industries involved are almost infiltrated into all aspects of social development. However, the environmental protection department currently has insufficient authority to support its work, resulting in environmental protection work that can only be stagnant in planning, monitoring and supervision. On the one hand, while regulating environmentally relevant behaviors, they have little punishment power, making some measures such as "paper talk" difficult to implement, and environmental protection work is not smooth. On the other hand, the joint prevention and control policy at this stage mainly relies on the government to implement, and the public participation is not enough. The air pollution control itself is a large-scale project, which requires the broad public power of the public to promote. To a certain extent, the cross-regional public problems need to force the government to switch from management administration to cooperative administration, and to include the public in the main body of environmental governance. 3) At the micro level, the local government's GDP theory lacks a dynamic mechanism. At present, local government officials cannot present themselves to the public in the face of the responsible party. Inadequate action, mutual refusal and afterwards, has become the norm of the Chinese government officialdom. Due to China's vast territory and obvious division of administrative areas, coupled with the decentralization of central power in recent years, the local authorities have greater autonomy, which has led local governments to accustom to abandon external interference and seek regional development. The short-sighted view of interests of local governments led to the evasion of governance consciousness, which prompted local government officials to succumb to the practice of air pollution control in order to seek promotion, and feared that they could not reflect their political achievements and consciously evade the behavior of pollution control. This evasiveness of consciousness is mainly manifested in the inaction of local government administration.

\subsection{Subregional Results by Economic Level}

Because the environmental Kuznets curve hypothesis holds that economic de- 
velopment and pollution emissions are in a " $U$ "-type nonlinear relationship, the environmental willingness of residents and the government will rise with the increase of living standards per capita. Therefore, the level of economic development has reached a certain level. Environmental pollution will decrease with the increase of economic level, that is, the difference in emission reduction between different affected areas of economic development. Therefore, we assume that the economically developed large cities have lower environmental pollution and better policy implementation than small and medium-sized cities. In order to more accurately study the impact of economic level differences on the pollution control of key prevention and control urban agglomerations, this paper refines 53 cities into two parts: high economic level cities and low and medium economic level cities, and compares and analyzes these two parts, as shown in Table 3.

According to the results of subregional regression, the policy has different inhibitory effects on sulfur dioxide pollution in cities with different economic levels. The policy has a significant inhibitory effect on sulfur dioxide pollution in high-economic cities, while the impact on low- and medium-economic cities is not significant. This may be more environmentally friendly with larger cities with more developed economies. They also use themselves to become important regional economic centers and tourist cities. In contrast, cities with low and medium economic levels have less policy implementation, supervision and resource input than high-level cities. However, from the perspective of pollutant industry dust, regardless of the level of economic level, the policy has no significant effect on the suppression of industrial soot pollution, which again confirms the analysis results.

Regarding the urban location factor, regardless of the economic level, the difference in the impact of urban location factors on the emission reduction of the two pollutants is not significant. Compared with the Beijing-Tianjin-Hebei region, the implementation of the joint prevention and control policy in the Yangtze River Delta region and the Pearl River Delta region has a greater inhibitory effect on industrial soot emissions than the Beijing-Tianjin-Hebei region. It can be seen that the industrial smoke emission in the Beijing-Tianjin-Hebei region has the weakest emission reduction effect; In the high-economic level cities, the policy of reducing sulfur dioxide in the Beijing-Tianjin-Hebei region has the weakest emission reduction effect. The overall result is similar to the previous one.

From the perspective of other control variables, the factors that have a significant impact on pollutant emission reduction are the per capita GDP level, the industrial structure measured by the secondary industry, and the level of urbanization. The coefficient symbols are consistent with the previous ones. This reflects that regardless of the development of the economic level, the growth of per capita living standards and the acceleration of urbanization in the three regions will promote pollution reduction, while the traditional non-green industrial structure based on the secondary industry will increase environmental pollution. 
Table 3. Regression results in different economic levels.

\begin{tabular}{|c|c|c|c|c|}
\hline & \multicolumn{2}{|c|}{$\begin{array}{l}\text { Sulfur dioxide emission intensity } \\
\qquad \operatorname{lnSI}\end{array}$} & \multicolumn{2}{|c|}{$\begin{array}{l}\text { Industrial soot emission intensity } \\
\operatorname{lnMI}\end{array}$} \\
\hline & $\begin{array}{l}\text { High economic } \\
\text { level }\end{array}$ & $\begin{array}{l}\text { Low to medium } \\
\text { economic level }\end{array}$ & $\begin{array}{c}\text { High economic } \\
\text { level }\end{array}$ & $\begin{array}{l}\text { Low to medium } \\
\text { economic level }\end{array}$ \\
\hline \multicolumn{5}{|l|}{ Independent variable } \\
\hline Policy $_{t}$ & $\begin{array}{c}-1.4694^{* *} \\
(-2.07)\end{array}$ & $\begin{array}{l}0.2463 \\
(0.34)\end{array}$ & $\begin{array}{l}0.6276 \\
(0.57)\end{array}$ & $\begin{array}{l}1.4192 \\
(0.75)\end{array}$ \\
\hline $\mathrm{YRD}_{i} \times$ Policy $_{t}$ & $\begin{array}{l}-0.0276 \\
(-0.23)\end{array}$ & $\begin{array}{l}0.0403 \\
(0.29)\end{array}$ & $\begin{array}{l}-0.1717 \\
(-0.59)\end{array}$ & $\begin{array}{l}-0.2121 \\
(-0.62)\end{array}$ \\
\hline $\mathrm{PRD}_{i} \times$ Policy $_{t}$ & $\begin{array}{c}-0.0932 \\
(-0.49)\end{array}$ & $\begin{array}{c}0.0224 \\
(0.17)\end{array}$ & $\begin{array}{l}-0.0641 \\
(-0.16)\end{array}$ & $\begin{array}{c}-0.1561 \\
(-0.41)\end{array}$ \\
\hline \multicolumn{5}{|l|}{ Control variable } \\
\hline $\operatorname{lnPGDP}_{i t}$ & $\begin{array}{c}-0.1616 \\
(-0.77)\end{array}$ & $\begin{array}{c}-0.9988^{\star *} \\
(-2.42)\end{array}$ & $\begin{array}{c}-0.7977^{* * *} \\
(-4.23)\end{array}$ & $\begin{array}{c}-1.4763^{*} \\
(-1.93)\end{array}$ \\
\hline $\operatorname{lnSTR} \operatorname{sit}_{i t}$ & $\begin{array}{l}1.5317^{* * *} \\
(2.76)\end{array}$ & $\begin{array}{l}1.7937^{* * *} \\
(2.84)\end{array}$ & $\begin{array}{c}2.6028^{* * *} \\
(4.04)\end{array}$ & $\begin{array}{l}1.6790 \\
(1.57)\end{array}$ \\
\hline $\operatorname{lnPOP} i t$ & $\begin{array}{c}-0.5406 \\
(-1.11)\end{array}$ & $\begin{array}{l}0.3971 \\
(0.46)\end{array}$ & $\begin{array}{c}-0.9923 \\
(-1.16)\end{array}$ & $\begin{array}{c}-0.3093 \\
(-0.12)\end{array}$ \\
\hline $\ln \mathrm{UR}_{i t}$ & $\begin{array}{c}-0.1536 \\
(-1.21)\end{array}$ & $\begin{array}{c}-0.2208^{* *} \\
(-2.43)\end{array}$ & $\begin{array}{l}-0.2878 \\
(-1.47)\end{array}$ & $\begin{array}{c}-0.0982 \\
(-0.34)\end{array}$ \\
\hline $\operatorname{lnSC} C_{i t}$ & $\begin{array}{c}-0.0050 \\
(-0.06)\end{array}$ & $\begin{array}{l}-0.0269 \\
(-0.56)\end{array}$ & $\begin{array}{l}-0.1620 \\
(-1.25)\end{array}$ & $\begin{array}{l}-0.1215 \\
(-0.86)\end{array}$ \\
\hline $\operatorname{lnFE} E_{i t}$ & $\begin{array}{l}0.0515 \\
(0.14)\end{array}$ & $\begin{array}{c}-0.0392 \\
(-0.15)\end{array}$ & $\begin{array}{l}0.0825 \\
(0.16)\end{array}$ & $\begin{array}{r}0.2990 \\
(0.50)\end{array}$ \\
\hline $\operatorname{lnRD_{it}}$ & $\begin{array}{c}-0.0163 \\
(-0.21)\end{array}$ & $\begin{array}{c}-0.0535 \\
(-0.64)\end{array}$ & $\begin{array}{c}0.0195 \\
(0.17)\end{array}$ & $\begin{array}{c}-0.1103 \\
(-0.75)\end{array}$ \\
\hline $\operatorname{lnFI} I_{i t}$ & $\begin{array}{l}-0.0638 \\
(-0.68)\end{array}$ & $\begin{array}{l}-0.0178 \\
(-0.31)\end{array}$ & $\begin{array}{r}-0.1443 \\
(-1.08)\end{array}$ & $\begin{array}{l}-0.0135 \\
(-0.17)\end{array}$ \\
\hline Constant term & $\begin{array}{l}2.4940 \\
(0.55)\end{array}$ & $\begin{array}{l}3.5869 \\
(0.61)\end{array}$ & $\begin{array}{l}5.5397 \\
(0.81)\end{array}$ & $\begin{array}{c}10.0621 \\
(0.57)\end{array}$ \\
\hline Time Effect & $\sqrt{ }$ & $\sqrt{ }$ & $\sqrt{ }$ & $\sqrt{ }$ \\
\hline Individual Effect & $\sqrt{ }$ & $\sqrt{ }$ & $\sqrt{ }$ & $\sqrt{ }$ \\
\hline Observations & 377 & 312 & 377 & 312 \\
\hline Within $\mathrm{R}^{2}$ & 0.8706 & 0.6810 & 0.4740 & 0.2702 \\
\hline
\end{tabular}

Note: 1) The values in parentheses are t values; 2$){ }^{* * *},{ }^{* *}$, and ${ }^{*}$ indicate significant statistical levels at $1 \%$, $5 \%$, and $10 \%$, respectively; 3) All models consider heteroscedasticity, Statistical inference was made using clustering robust standard errors with clustering variables for each city. Source: Author use stata14.0 software to calculate.

On the whole, the results of sub-regional regression show that: 1) From the perspective of policy effects, the joint prevention and control policy has a significant effect on reducing sulfur dioxide emissions in economically developed cities, but the effect of policies on industrial soot emissions is not significant regardless of economic development; The Beijing-Tianjin-Hebei region is the least optimistic region among the three major regions. 2) From the influencing factors, the growth of per capita living standards and the process of urbanization 
can promote the reduction of urban pollutants regardless of the level of economic level; while the traditional non-green industrial structure dominated by the secondary industry is not conducive to pollution reduction.

\subsection{Robust Test}

In practice, the interpretation ability of the evaluation method and the index may be deviated due to the difference in parameter settings. The robust test mainly examines whether the evaluation methods and indicators will maintain a consistent and stable estimate of the results when certain parameters are changed. That is, change a specific parameter and observe whether the empirical result changes with the change of the parameter setting. If the symbol and saliency of the result change, the result is not stable. This section will test the robustness of the overall results of the region in Table 2. From the measurement method, the stability of the results of Table 2 is based on the OLS estimate and the RE estimate.

According to Table 4, compared with the original FE estimation results, the

Table 4. OLS estimation and RE estimation result.

\begin{tabular}{|c|c|c|c|c|c|c|}
\hline & \multicolumn{3}{|c|}{$\begin{array}{l}\text { Sulfur dioxide emission intensity } \\
\qquad \ln S I\end{array}$} & \multicolumn{3}{|c|}{$\begin{array}{l}\text { Industrial soot emission intensity } \\
\qquad \ln \mathrm{MI}\end{array}$} \\
\hline & OLS & $\mathrm{RE}$ & $\mathrm{FE}$ & OLS & $\mathrm{RE}$ & $\mathrm{FE}$ \\
\hline \multicolumn{7}{|l|}{$\begin{array}{l}\text { Independent } \\
\text { variable }\end{array}$} \\
\hline Policy $_{t}$ & $\begin{array}{l}0.0760 \\
(0.45)\end{array}$ & $\begin{array}{l}-0.1181 \\
(-1.59)\end{array}$ & $\begin{array}{l}-0.7628 \\
(-1.36)\end{array}$ & $\begin{array}{l}0.9801^{* * *} \\
(3.18)\end{array}$ & $\begin{array}{l}0.5679^{* * *} \\
(2.74)\end{array}$ & $\begin{array}{l}0.6305 \\
(0.62)\end{array}$ \\
\hline $\mathrm{YRD}_{i} \times$ Policy $_{t}$ & $\begin{array}{l}-0.3996^{* * *} \\
(-2.70)\end{array}$ & $\begin{array}{l}-0.0660 \\
(-0.86)\end{array}$ & $\begin{array}{c}-0.0678 \\
(-0.79)\end{array}$ & $\begin{array}{c}-0.4817^{*} \\
(-1.76)\end{array}$ & $\begin{array}{l}-0.2599 \\
(-1.14)\end{array}$ & $\begin{array}{l}-0.3065 \\
(-1.32)\end{array}$ \\
\hline $\mathrm{PRD}_{i} \times$ Policy $_{t}$ & $\begin{aligned}-0.7107^{* * *} & (-3.25)\end{aligned}$ & $\begin{array}{l}-0.0913 \\
(-0.72)\end{array}$ & $\begin{array}{l}-0.0716 \\
(-0.59)\end{array}$ & $\begin{array}{l}-1.1798^{* * *} \\
(-3.25)\end{array}$ & $\begin{array}{l}-0.2818 \\
(-0.96)\end{array}$ & $\begin{array}{l}-0.2058 \\
(-0.69)\end{array}$ \\
\hline \multicolumn{7}{|l|}{ Control variable } \\
\hline $\ln \mathrm{PGDP}_{i t}$ & $\begin{array}{l}-0.2000 \\
(-0.90)\end{array}$ & $\begin{array}{c}-0.3008^{\star *} \\
(-1.98)\end{array}$ & $\begin{array}{l}-0.3224 \\
(-1.63)\end{array}$ & $\begin{array}{c}-0.1632 \\
(-0.57)\end{array}$ & $\begin{array}{c}-0.6337^{\star * *} \\
(-4.40)\end{array}$ & $\begin{array}{c}-0.8490^{\star * *} \\
(-4.46)\end{array}$ \\
\hline $\operatorname{lnSTR}_{i t}$ & $\begin{array}{c}1.4267^{* * *} \\
(4.16)\end{array}$ & $\begin{array}{c}1.8547^{* * *} \\
(4.86)\end{array}$ & $\begin{array}{l}1.5978^{* * *} \\
(3.45)\end{array}$ & $\begin{array}{l}1.2943^{* *} \\
(2.21)\end{array}$ & $\begin{array}{l}1.6584^{* * *} \\
(2.76)\end{array}$ & $\begin{array}{c}1.6840^{* *} \\
(2.41)\end{array}$ \\
\hline $\ln \mathrm{POP}_{i t}$ & $\begin{array}{l}-0.2483 \\
(-1.51)\end{array}$ & $\begin{array}{l}-0.1954 \\
(-0.98)\end{array}$ & $\begin{array}{l}-0.5333 \\
(-1.23)\end{array}$ & $\begin{array}{c}-0.3544^{*} \\
(-1.74)\end{array}$ & $\begin{array}{c}-0.4428^{*} \\
(-1.86)\end{array}$ & $\begin{array}{l}-0.9603 \\
(-1.18)\end{array}$ \\
\hline $\ln \mathrm{UR}_{i t}$ & $\begin{array}{c}0.1678 \\
(1.48)\end{array}$ & $\begin{array}{l}-0.1254^{* *} \\
(-2.32)\end{array}$ & $\begin{array}{c}-0.2360^{* * *} \\
(-3.83)\end{array}$ & $\begin{array}{r}-0.0090 \\
(-0.07)\end{array}$ & $\begin{array}{l}-0.0819 \\
(-0.57)\end{array}$ & $\begin{array}{l}-0.1912 \\
(-1.03)\end{array}$ \\
\hline $\operatorname{lnSC} C_{i t}$ & $\begin{array}{l}0.0103 \\
(0.08)\end{array}$ & $\begin{array}{l}-0.0354 \\
(-0.63)\end{array}$ & $\begin{array}{c}-0.0173 \\
(-0.30)\end{array}$ & $\begin{array}{c}-0.2495 \\
(-1.48)\end{array}$ & $\begin{array}{l}-0.1194 \\
(-1.38)\end{array}$ & $\begin{array}{l}-0.1537 \\
(-1.52)\end{array}$ \\
\hline $\operatorname{lnFE} E_{i t}$ & $\begin{array}{c}-0.2460^{* *} \\
(-2.03)\end{array}$ & $\begin{array}{c}-0.3087^{* *} \\
(-2.55)\end{array}$ & $\begin{array}{c}-0.0142 \\
(-0.06)\end{array}$ & $\begin{array}{c}-0.1820 \\
(-1.25)\end{array}$ & $\begin{array}{l}0.0775 \\
(0.54)\end{array}$ & $\begin{array}{l}0.2174 \\
(0.57)\end{array}$ \\
\hline $\operatorname{lnRD_{it}}$ & $\begin{array}{c}-0.1750^{* * \star} \\
(-2.73)\end{array}$ & $\begin{array}{c}-0.0969^{* * *} \\
(-3.29)\end{array}$ & $\begin{array}{c}-0.0832^{\star} \\
(-1.75)\end{array}$ & $\begin{array}{c}-0.1240^{*} \\
(-1.68)\end{array}$ & $\begin{array}{c}-0.1168^{\star * *} \\
(-2.87)\end{array}$ & $\begin{array}{c}-0.0427 \\
(-0.50)\end{array}$ \\
\hline $\operatorname{lnFI}_{i t}$ & $\begin{array}{c}-0.0834 \\
(-0.97)\end{array}$ & $\begin{array}{l}0.0167 \\
(0.34)\end{array}$ & $\begin{array}{c}-0.0364 \\
(-0.72)\end{array}$ & $\begin{array}{l}-0.1065 \\
(-0.90)\end{array}$ & $\begin{array}{c}-0.0696 \\
(-1.00)\end{array}$ & $\begin{array}{c}-0.0662 \\
(-0.86)\end{array}$ \\
\hline
\end{tabular}




\begin{tabular}{|c|c|c|c|c|c|c|}
\hline \multicolumn{7}{|l|}{ Continued } \\
\hline Constant term & $\begin{array}{c}2.0403 \\
(0.81)\end{array}$ & $\begin{array}{l}1.6816 \\
(0.78)\end{array}$ & $\begin{array}{c}3.5342 \\
(0.99)\end{array}$ & $\begin{array}{c}0.7344 \\
(0.21)\end{array}$ & $\begin{array}{l}3.8387 \\
(1.35)\end{array}$ & $\begin{array}{l}8.6585 \\
(1.41)\end{array}$ \\
\hline Time Effect & & & $\sqrt{ }$ & & & $\sqrt{ }$ \\
\hline Individual Effect & & & $\sqrt{ }$ & & & $\sqrt{ }$ \\
\hline Observations & 689 & 689 & 689 & 689 & 689 & 689 \\
\hline Overall $\mathrm{R}^{2}$ & & 0.5481 & & & 0.4345 & \\
\hline Adjusted $\mathrm{R}^{2}$ & 0.4730 & & & 0.5922 & & \\
\hline Within $\mathrm{R}^{2}$ & & & 0.7838 & & & 0.3465 \\
\hline
\end{tabular}

Note: The value in the brackets of the 1) RE estimation result is the $\mathrm{z}$ value, and the values in the brackets of the OLS estimation and the FE estimation result are both $\mathrm{t}$ values; 2$)^{* * *}$, ${ }^{* *}$, and ${ }^{*}$ are expressed at $1 \%, 5 \%$, and 10, respectively. The statistical level of \% is significant; 3 ) All models consider the heteroscedasticity problem, and statistical inference is made using clustering robust standard errors with clustering variables in each city. Source: Author use stata14.0 software to calculate.

OLS and RE estimation results show that the policy coefficient of industrial soot emission intensity is significantly positive, which is consistent with the results of the FE model in Table 2 which only controls the individual fixed effect. Indirectly supporting the FE regression results that control the single fixed effect, still reflects the fact that industrial dust emission reduction is not optimistic. In fact, China's current smoke detection technology is not perfect enough to distinguish between water vapor and smoke in the smoke, plus for major soot emitters with more production lines, such as ceramic enterprises, the cost of ultra-low emission conversion for each production line is very high, which increases the difficulty of reducing soot emissions. Therefore, despite the country's introduction of ultra-low emission reduction schemes for soot, soot emission reduction situation is still not optimistic. In addition, the cross-variables of the two pollutants added to the urban location factor have a significant negative result in the OLS estimation, indicating that the OLS estimate, the policy for the reduction of two pollutants in the Yangtze River Delta region and the Pearl River Delta region The effect is obviously superior to the Beijing-Tianjin-Hebei region, supporting the conclusions of the previous article. The Beijing-Tianjin-Hebei region may have a relatively simple industrial structure and a serious dependence on coal energy, making it difficult to control the source of pollution emissions, and the regional economic development imbalance leads to regional governance objectives and the standard is difficult to unify and other resistance, making the policy effect lag behind the other two regions. Comparing the three estimation results, the estimation coefficients of all variables are consistent, the saliency is basically the same and the estimated values are small, and the overall results can support the robustness of the model.

\section{Conclusions and Policy Suggestions}

\subsection{Conclusions}

The identification of China's joint defense policy effect and the identification of 
the socio-economic roots that affect pollution emissions are prerequisites for the improvement and effective implementation of government emission reduction policies. Based on the panel data of 53 prefecture-level cities from 2004 to 2016, this paper empirically tests the policy effects of China's joint defense control on the three key governance areas of Beijing-Tianjin-Hebei, Yangtze River Delta and Pearl River Delta. The research shows: 1) In the overall China Joint Defense, although the joint control mechanism has played a role in preventing and controlling the emission reduction of the city to a certain extent, the effect is not significant. 2) The emission reduction situation in Beijing-Tianjin-Hebei region is the least optimistic. 3) Industrial dust emission reduction is still a policy difficulty. From the influencing factors: 1) Large cities with developed economies have more advantages to control pollution. 2) Residents' participation is a key part of multi-dimensional governance and plays an important role in government emission reduction policies. 3) The economies of scale and agglomeration brought about by the urbanization process have led to continuous optimization of industrial structure, rapid technological innovation, and environmental awareness in large cities, all of which are conducive to a cleaner city. 4) Multi-city governance of cities has increasingly become an innovative path of urban governance. In the face of complicated urban governance problems, it is difficult to carry out work by relying on the government alone. Residents are the mainstay of the city and should be the protagonist of governance. 5) Emission reduction still needs technical support. For example, the Pearl River Delta region has promoted emission reduction through the introduction of environmental protection technology through foreign capital with its highly open conditions. The vigorous development of environmental protection work is inseparable from technological progress. 6) The traditional industrial structure is a major obstacle to the emission reduction policy. The industrial structure with high abnormality has led to an increase in air pollution in China, which is a resistance to current environmental policies.

\subsection{Policy Suggestions}

In terms of how to improve the existing regional joint prevention and control mechanism and promote China's regional collaborative governance, this paper proposes the following policy recommendations: 1) Broaden the governance path and build a multi-subject cooperation system. Air pollution control is a large-scale systematic project. Under the joint prevention and control mechanism, the role of the public cannot be ruled out. The cooperation between the government and the public can inject vitality into the construction of diversified forces. 2) Aggregate the overall interests of the region and build an endogenous synergy mechanism. Specifically, it is necessary to clarify the respective responsibilities of local governments within the region, form a unified legal system, monitoring platform, information mechanism, early warning mechanism, etc., and establish horizontal compensation mechanisms, interest coordination 
mechanisms and "green GDP" among different entities within the region. The competition mechanism is used to aggregate government functions. 3) Implement a scientific top-level design to control air pollution from the source. On the one hand, it is possible to force the green upgrading of industrial structure through market-oriented environmental regulation tools, such as the regulation of emission rights futures in the emissions trading market, the collection of pollution taxes, the establishment of environmental protection funds and other market-incentive environmental regulations; On the other hand, guide enterprises to actively carry out green technology innovation activities and increase government investment in research and development of pollution prevention technologies; at the same time, the government should actively introduce foreign capital, and introduce projects without the sacrifice of the environment to achieve the purpose of opening up and environmentally coordinated development. The ability to digest, absorb and utilize imported technical equipment, fully absorb advanced foreign environmental protection technologies, and actively exert the technological spillover effects of foreign trade. 4) Conduct global planning based on governance differences and implement a focused regional governance strategy. For example, it is necessary to distinguish the similarities and differences between the Pearl River Delta and the Beijing-Tianjin-Hebei region and the Yangtze River Delta in terms of economic structure, population agglomeration, geographic topography, and climatic conditions, and draw on and learn from the experience of the Pearl River Delta to implement a regional environmental plan tailored to local conditions; Different management effects, try to integrate the existing environmental policy system, establish a comprehensive environmental protection technology system, improve the environmental productivity of existing dust removal technologies, and at the same time improve the environmental problems of multi-pollutants; The resulting air pollution control capacity is unbalanced, and the inter-city ecological compensation mechanism should be adopted as soon as possible to give the backward areas the right to seek green development while preventing the leakage of air pollution between different regions.

\section{Conflicts of Interest}

The authors declare no conflicts of interest regarding the publication of this paper.

\section{References}

[1] Chang, J.W. (2010) Unification of Extraterritorial Reference and Local Innovation: Interpretation of Guiding Opinions on Promoting Air Pollution Joint Prevention and Control Work to Improve Regional Air Quality (I). Environmental Protection, No. 10, 8-11.

[2] Chang, J.W. (2010) Unification of Extraterritorial Reference and Local Innovation: Interpretation of Guiding Opinions on Promoting Air Pollution Joint Prevention and Control Work to Improve Regional Air Quality (Part II). Environmental Pro- 
tection, No. 11, 10-12.

[3] Yang, W. and Sun, T. (2009) Research on Cross-Regional Environmental Governance and Local Government Cooperation Mechanism. Administration in China, No. 1, 66-69.

[4] Zhang, S.Q., Wan, W. and He, P. (2015) Cooperative Mechanism and Policy Discussion of Regional Atmospheric Environmental Quality Management. Environmental Management of China, 7, 44-50.

[5] Hoel, M. (1991) Global Environment Problems: The Effects of Unilateral Actions Taken by One Country. Journal of Environmental Economics and Management, 20, 55-70. https://doi.org/10.1016/0095-0696(91)90023-C

[6] Hoel, M. (1994) Efficient Climate Policy in the Presence of Free Riders. Journal of Environmental Economics and Management, 27, 259-274. https://doi.org/10.1006/jeem.1994.1038

[7] Carraro, C. and Siniscalco, D. (1991) Strategies for the International Protection of the Environment. Journal of Public Economics, 52, 309-328. https://doi.org/10.1016/0047-2727(93)90037-T

[8] John, A. and Charles, F. (2001) Mason Optimal Institution Arrangements for Transboundary Pollution in a Second-Best World: Evidence from a Differential Game with Asymmetric Players. Journal of Environmental Economics and Management, 42, 277-296. https://doi.org/10.1006/jeem.2000.1163

[9] Shi, Z.L. and Bi, L.L. (2007) Study on the Management Mechanism of Water Pollution Control in China's Inter-Regional River Basin-Taking Water Pollution Control at the Border of Jiangsu and Zhejiang Province as an Example. China Population, Resources and Environment, No. 3, 3-9.

[10] He, Y. (2006) Interstate Agreement-Intergovernmental Coordination Mechanism in the United States. Journal of National School of Administration, No. 2, 88-91.

[11] Wan, W. (2009) Regional Environmental Management Mechanism: International Experience and Reference. Chinese Academy of Environmental Sciences. Proceedings of the 2009 Annual Conference of the Chinese Society of Environmental Sciences (3), Chinese Society of Environmental Sciences, 10.

[12] Zheng, J. (2017) Enlightenment of China’s Long-Term Mechanism of Air Pollution Prevention and Control Cooperation across China to China. Environmental Protection, 45, 75-77.

[13] Zhao, X.F. and Yuan, Z.W. (2014) Study on the Coordination of Air Pollution Control Policy among Regional Governments in Beijing, Tianjin and Hebei. Administration in China, No. 11, 18-23.

[14] Zhang, S.Q. (2014) Integration of Beijing-Tianjin-Hebei and Regional Air Quality Management. Environmental Protection, 42, 30-33.

[15] Liu, D.H., Zhang, H.Y. and Bi, J. (2017) Study on the Driving Mechanism of Regional Air Pollution Collaborative Governance-Taking the Yangtze River Delta Region as an Example. China Environmental Management, 9, 73-79.

[16] Huo, Y. (2012) Study on the Integration of Air Pollutants Emission Trading in the Yangtze River Delta. Ecological Economy, No. 12, 181-184 + 188.

[17] Li, L. and Research Group of Shanghai Academy of Environmental Sciences (2016) Deepening the Linkage Research on Air Pollution Prevention and Control in the Yangtze River Delta Region. Science Development, No. 2, 76-85.

[18] Wang, S., Zhang, Y., Zhong, L., Li, J. and Yu, Q. (2005) The Mutual Influence of Air Pollution between Cities in the Pearl River Delta. Chinese Environmental Science, 
No. 2, 133-137.

[19] Xie, W. (2015) Preliminary Study on Comprehensive Control of Air Pollution in Foshan. Economic Research Guide, No. 3, 214-215.

[20] Wang, Y. (2011) The Construction of Environmental Cooperation Mechanism in the Pearl River Delta. Journal of Guangdong Administration Institute, 23, 10-17.

[21] Wang, Y. (2017) Composite Incentive Mechanism for Constructing Urban Group Environmental Governance Cooperation. Theory Monthly, No. 7, 130-135.

[22] Cremer, H. and Gahvari, F. (2004) Environmental Taxation, Tax Competition, and Harmonization. Journal of Urban Economics, 55, 21-45. https://doi.org/10.1016/j.jue.2003.07.003

[23] Piciu, G.C. and Trica, C.L. (2012) Trends in the Evolution of Environmental Taxes. Procedia Economics and Finance, 3, 716-721. https://doi.org/10.1016/S2212-5671(12)00219-5

[24] Guo, Y. and Yan, H. (2016) Legal and Economic Analysis of Local Air Pollutant Emissions Trading Mechanism-Based on the Requirements of Total Control. Economic Issues, No. 4, 51-54.

[25] Wang, F. (2006) On the Principles and Mechanisms of Ecological Compensation. Study on Dialectics of Nature, No. 1, 31-35.

[26] Li, P. and Sun, W. (2010) Study on Regional Ecological Compensation Mechanism from the Perspective of Economic Geography. Acta Ecologica Sinica, 19, 1507-1512.

[27] Liu, W. (2015) Study on the Establishment of the Ecological Compensation Model for Air Pollution in Beijing, Tianjin and Hebei. Management Modernization, 35, 64-65+120.

[28] Li, Y. (2005) Public Participation and Improvement of Legal System for Prevention and Control of Air Pollution. Administration in China, No. 3, 52-54.

[29] Zhang, H. and Mu, Z. (2015) Declaring War on Air Pollution with Strict Legal System-Review and Perfection of "Air Pollution Prevention and Control Law (Revised Draft)". Environmental Protection, 43, 45-47.

[30] Chang, J. (2014) New Environmental Protection Law: The Most Stringent in History but the Most Difficult to Implement. Environmental Protection, 42, 23-28.

[31] Chang, J. (2014) The Joint Prevention and Control of Air Pollution Area Should Implement the Principle of Common but Differentiated Responsibility. Environmental Protection, 42, 43-45.

[32] Yan, C. (2012) Social Capital, Innovation and Long-Term Economic Growth. Economic Research, 47, 48-60.

[33] Lv, C. and Li, Y. (2017) The Difference between Urban Emission Reduction and Air Pollution Prevention and Control under the Outbreak of Smog Theory. Economic Geography, 37, 148-154.

[34] Zhang, C., Lu, W., Guo, L. and Yu, T. (2011) Environmental Regulation Strength, Production Technology Progress. Economic Research, 46, 113-124.

[35] Bao, Q. and Peng, S. (2006) Economic Growth and Environmental Pollution: Estimation of Simultaneous Equations Based on Panel Data. World Economy, No. 11, 48-58.

[36] Du, W. and Xia, Y. (2018) Is the Synergistic Treatment of Smog in the Beijing-Tianjin-Hebei Region Effective?-Based on the Analysis of the Double Difference Model. Contemporary Economic Management, No. 9, 1-10. 